\title{
Endoscopic Ultrasonography in the Evaluation of Gastric Polyps in Juvenile Polyposis
}

Juvenile polyposis is a rare condition characterized by the occurrence of multiple juvenile polyps in the gastrointestinal tract. Most cases appear in the second decade of life, with rectal bleeding and anemia. In approximately $25 \%$ of cases, there is a family history of juvenile polyposis, inherited as an autosomal dominant trait $(1,2)$. Ninety-eight percent of the patients have polyps in the colon, whereas polyps in the stomach and duodenum occur less frequently. Recently, Hofting et al. (3) found that $16 \%$ of patients with juvenile polyposis have polyps in the stomach or duodenum, but clear data on the incidence of upper gastrointestinal polyps are not available, since upper endoscopy has not been part of the routine surveillance until recently $(3,4)$.

Juvenile polyps range from a few millimeters to several centimeters in size. The smaller polyps are sessile, or have a short stalk with a smooth, red surface. The larger polyps are pedunculated, with a lobulated, papillary red or brown surface. The larger ones in particular are often superficially ulcerated, and can be seen to contain cystic spaces microscopically. The classic juvenile polyp consist of dilated cystic glands, lined by tall columnar epithelium. There is overgrowth of lamina propria, which is edematous and infiltrated by inflammatory cells (Figure 1). Large polyps may contain areas with dysplastic epithelium, and it has recently become clear that juvenile polyposis may be a premalignant condition (4-7). Most cases of carcinoma arise in the colon or rectum, but carcinoma of the stomach has also been reported $(8,9)$.

We report here the case of a 21-year-old woman who presented in 1969 with a history of diarrhea and abdominal pain during the previous six months. At laparotomy, a juvenile polyp $5 \times 5 \times 6 \mathrm{~cm}$ in size was removed from the cecum. One year later, six juvenile polyps were removed from the ascending colon at colonoscopy and during laparotomy. In 1983, the patient had an episode of rectal bleeding, and subsequent colonoscopy showed an adenocarcinoma of the cecum $3 \times 4 \times 4 \mathrm{~cm}$ in size. A right-sided hemicolectomy was performed. The resected colon was additionally found to contain large numbers of small juvenile polyps. In 1987, a juvenile polyp was removed from the left colonic flexure. At the same time, upper endoscopy was performed, showing innumerable small polyps in the gastric antrum and fundus. The polyps were shown to be juvenile or hyperplastic polyps by histological examination. During a regular one-year surveillance, no recurrence of the colonic polyps was found. However, the small polyps persisted in the stomach and duodenum. At a regular check-up in 1995 , a tumor $10 \times 5 \times 6 \mathrm{~cm}$ in size was surprisingly found in the distal part of the gastric body at the lesser curvature. Due to the size and alarming appearance of the lesion, EUS was carried out with an Olympus echo endoscope (GF-UM3). EUS demonstrated a large, sessile polyp, but apparently only the mucosa was involved, leaving the submucosa and the muscularis propria layer intact (Figure 2). The base of the polyp was located at the lesser curvature, measuring $7 \mathrm{~cm}$ in diameter. Repeated endoscopic forceps biopsy confirmed the benign condition of a juvenile polyp.

Endoscopic snare polypectomy was considered, but due to the spatial extension of the polyp, partial gastrectomy was decided on. Subsequently, histological examination of the resected specimen showed no dysplasia or carcinoma, and confirmed the diagnosis of juvenile polyposis.

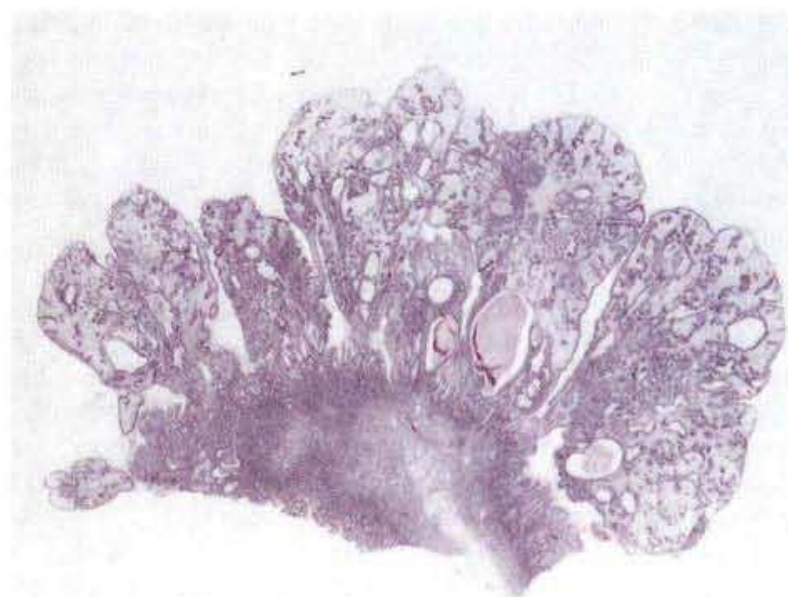

Figure 1: Histological specimen of part of the gastric juvenile polyp. showing some of the characteristics described

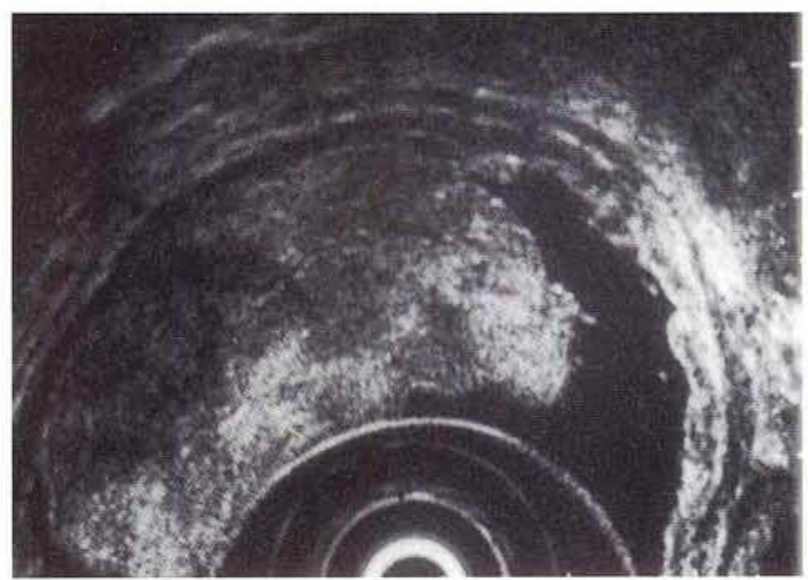

Figure 2: Endosonography of the large benign juvenile gastric polyp, with the third and fourth layers intact.

Juvenile polyposis is a premalignant condition, predominantly of the colon. When therapy is being planned, the number and size of the polyps should be considered, and in the case of large polyps or a large number of polyps in the colon, a colectomy should be performed. Since gastric carcinoma has also been reported in patients with juvenile polyposis, these patients should undergo follow-up by both upper and lower endoscopy. The preferred treatment for gastric polyps is endoscopic resection. However. large polyps and polyps with signs of malignancy require surgical resection.

EUS has been shown to be reliable in assessing the extent of gastric tumors, especially in relation to cancer staging $(10,11)$. The present case suggests that EUS is also valuable in evaluating patients with juvenile polyposis presenting with polyps of the stomach, since the actual EUS combined with biopsies suggested a benign lesion, and we were therefore able to plan a limited surgical resection of the stomach. 
We believe that EUS in addition to endoscopy with biopsies should be recognized as the method of choice for pre-therapeutic evaluation in patients with gastric polyps, since it is reliable and safe, and provides valuable information concerning the extent of the disease.

H. J. Gyrtrup ${ }^{\text {t, M. Siemsen }}$, P. Vilmann', A. M. Mogensen ${ }^{2}$

${ }^{\prime}$ Dept. of Surgery C

${ }^{2}$ Dept. of Pathology, Rigshospitalet, University of

Copenhagen, Copenhagen, Denmark

\section{References}

1. Desai DC, Neale KF, Talbot EC, Hodgson SV, Phillips RKS. Juvenile polyposis. Br J Surg 1995; 82: 14-7.

2. Harned RK, James LB, Sobin LH. The hamartomatous polyposis syndromes: clinical and radiological features. Am J Radiol 1995; 164: 565-71.

3. Hofting I, Pott G, Stolte M. Das Syndrom der juvenilen Polyposis. Leber Magen Darm 1993; 23: 107-12.

4. Järvinen HJ, Sipponen P. Gastroduodenal polyps in familial and juvenile polyposis. Endoscopy 1986; 18: 230-4.

5. Giadiello FM, Hamilton SR, Kern SE, et al. Colorectal neoplasia in juvenile polyposis or juvenile polyps. Arch Dis Child 1991; 66: 971-5.
6. O'Riordain DS, O'Dwyer PJ, Cullen AF, et al. Familial juvenile polyposis coli and colorectal cancer. Cancer 1991; 68: 889-92.

7. Subramony Q Scott-Connor CEH, Skelto D, Hall TJ. Familial juvenile polyposis: study of a kindred-evolution of polyps and relationship to gastrointestinal carcinoma. Am J Clin Pathol 1994; 26: 91-7.

8. Sassatelli R, Bertoni G, Serra G, et al. Generalized juvenile polyposis with mixed pattern and gastric cancer. Gastroenterology $1993 ; 104: 910-5$.

9. Yoshida T, Haraguchi A, Tanaka A, et al. A case of generalized juvenile polyposis associated with gastric carcinoma. Endoscopy $1988 ; 20: 33-5$.

10. Colin-Jones DG, Rösch T, Dittler HJ. Staging of gastric cancer by endoscopy. Endoscopy $1993 ; 25: 34-8$.

11. Rösch T. Endoscopic ultrasonography. Endoscopy 1994; 26: $148-68$

Corresponding Author

H. J. Gyrtrup

Vejrogade 6,2

2100 Copenhagen $\emptyset$

Denmark 